\title{
HUBUNGAN BISING DAN FUNGSI PENDENGARAN PADA TEKNISI MESIN KAPAL YANG BERSANDAR DI PELABUHAN BITUNG
}

\author{
${ }^{1}$ Nina P. Lumonang \\ ${ }^{2}$ Maya Moningka \\ ${ }^{2}$ Vennetia R. Danes \\ ${ }^{1}$ Kandidat Skripsi Fakultas Kedokteran Universitas Sam Ratulangi Manado \\ ${ }^{2}$ Bagian Fisika Fakultas Kedokteran Universitas Sam Ratulangi Manado \\ Email: n.lumonang_146@yahoo.com
}

\begin{abstract}
Noise is one of the unavoidable problems as a result of technological development. Hearing loss due to noise is called sensorineural hearing loss, which is oftenly not realized because it does not disturb daily conversation. Risk factors of hearing loss are inter alia noise intensity, length of employment, length of noise exposure in a day, and the usage of Ear Protective Equipment (EPE). This study aimed to determine the relationship between noise and hearing function among ship engine technicians in Bitung Port. This was an analytical study using a cross-sectional design. Samples consisted of 20 respondents. Noise measurement obtained noise intensities of $87 \mathrm{~dB}$ and $93 \mathrm{~dB}$. Of 20 respondents, there were 7 exposed to over a predetermined noise. The audiometric examination showed 3 of 20 respondents (15\%) with hearing loss. The bivariate analysis showed a significant relationship between hearing loss and noise intensity $(\mathrm{p}=0.008)$. Conclusion: There was a significant relationship between noise and hearing function among ship engine technicians in Bitung port.
\end{abstract}

Keywords: noise, ship engines technician, hearing

\begin{abstract}
Abstrak: Kebisingan merupakan salah satu masalah yang tidak dapat dihindari akibat kemajuan teknologi. Gangguan pendengaran akibat bising ialah tuli sensorineural, yang pada awalnya tidak disadari, karena belum mengganggu percakapan sehari-hari. Faktor resiko terjadinya tuli ialah antara lain intensitas bising, lama masa kerja, lama terpajan bising dalam sehari, ketaatan pemakaian Alat Pelindung Telinga (APT). Penelitian ini bertujuan untuk menentukan adanya hubungan antara bising dan fungsi pendengaran pada teknisi mesin kapal yang bersandar di Pelabuhan Bitung. Penelitian ini menggunakan metode analitik dengan rancangan potong lintang. Sampel berjumlah 20 orang. Hasil pengukuran kebisingan mendapatkan intensitas bising $87 \mathrm{~dB}$ dan $93 \mathrm{~dB}$. Dari 20 petugas hanya 7 orang yang bekerja melebihi NAB kebisingan yang telah ditetapkan. Hasil pemeriksaan dengan audiometri mendapatkan 3 orang (15\%) yang menderita tuli dan 17 orang (85\%) normal. Analisis bivariat menunjukkan terdapat hubungan bermakna antara gangguan pendengaran dan intensitas bising $(p=0,008)$. Simpulan: Terdapat hubungan bermakna antara bising dan fungsi pendengaran pada teknisi mesin kapal di pelabuhan Bitung.
\end{abstract}

Kata kunci: bising, teknisi mesin kapal, fungsi pendengaran

Penggunaan teknologi yang tinggi di tempat kerja dalam hal sarana dan prasarana menghasilkan suara atau bunyi atau kegaduhan yang tidak diinginkan akan menimbulkan gangguan kesehatan pada pekerja, yaitu terjadinya penyakit akibat kerja. Kebisingan merupakan salah satu faktor bahaya fisik yang sering dijumpai di tempat kerja. ${ }^{1}$

Gangguan pendengaran akibat bising 
ialah gangguan pendengaran yang disebabkan akibat terpajan oleh bising yang cukup keras dalam jangka waktu yang cukup lama, biasanya diakibatkan oleh bising lingkungan kerja. Sifat ketuliannya ialah tuli sensorineural koklea dan umumnya terjadi pada kedua telinga. ${ }^{2}$

Menurut Komnas PGPKT intensitas bising yang masih aman untuk telinga kita adalah sampai $80 \mathrm{~dB}$ dengan lamanya pajanan selama 24 jam tanpa penggunaan proteksi telinga seperti iPod, MP3, dan Timezone. $^{3}$

World Health Organisation (WHO, 2007), menyatakan bahwa prevalensi ketulian di Indonesia mencapai 4,2\%. Negara-negara di dunia telah menetapkan bahwa NIHL merupakan penyakit kerja yang terbesar diderita. Sebesar 16\% dari ketulian yang diderita oleh orang dewasa dikarenakan oleh kebisingan di tempat kerja, sehingga NIHL dapat dijadikan masalah yang perlu ditangani dan mendapatkan perhatian khusus. ${ }^{4}$

\section{METODE PENELITIAN}

Penelitian ini menggunakan metode survei analitik dengan pendekatan potong lintang. Penelitian dilakukan di Pelabuhan Laut Kota Bitung Sulawesi Utara pada bulan November 2014. Populasi adalah semua teknisi kapal di Pelabuhan Bitung.

Sampel penelitian diambil dengan memenuhi kriteria inklusi, yaitu: terdaftar sebagai teknisi mesin kapal di Pelabuhan Bitung; tidak ada infeksi telinga; telah bekerja minimal 6 bulan; bersedia sebagai subjek penelitian dengan mengisi lembar kuesioner, melakukan pemeriksaan fisik telinga dan audiometric; serta bersedia menandatangani informed consent.

Variabel penelitian terdiri dari variabel bebas yaitu kebisingan dan variabel terikat yaitu fungsi pendengaran. Pengumpulan data diperoleh dari kuesioner, pemeriksaan fisik telinga dan audiometri. Data dianalisis dengan uji Spearman (rho) dan program SPSS.

\section{HASIL PENELITIAN}

Tempat penelitian dilakukan di
Pelabuhan Bitung Kota Bitung, Sulawesi Utara. Pengukuran kebisingan dilakukan pada teknisi bagian mesin kapal dengan tingkat kebisingan $87 \mathrm{~dB}$ sampai $93 \mathrm{~dB}$.

Berdasarkan analisis univariat karakteristik responden dalam penelitian ini meliputi umur, lama menjadi petugas, tingkat kebisingan, ketaatan pemakaian Alat Pelindung Telinga (APT), jenis APT, dan gangguan pendegaran.

Tabel 1 menunjukkan bahwa responden yang berumur 20-30 tahun lebih banyak yaitu berjumlah 11 orang (55\%) dibandingan dengan kelompok umur $>40$ tahun (25\%) dan kelompok umur 30-40 tahun (20\%).

Tabel 1. Distribusi responden berdasarkan umur

\begin{tabular}{ccc}
\hline Kelompok Umur & $\mathrm{N}$ & $\%$ \\
\hline 20-30 Tahun & 11 & 55,0 \\
30-40 Tahun & 4 & 20,0 \\
>40 Tahun & 5 & 25,0 \\
Total & 20 & 100,0 \\
\hline
\end{tabular}

Tabel 2 menunjukkan lama kerja sebagai teknisi mesin kapal di Pelabuhan. Responden dengan lama kerja 1-10 tahun yang terbanyak yaitu 13 orang (65\%) dibandingkan dengan lama kerja $>10$ tahun (35\%).

Tabel 2. Distribusi responden berdasarkan lama kerja

\begin{tabular}{ccc}
\hline $\begin{array}{c}\text { Lama Kerja } \\
\text { (tahun) }\end{array}$ & $\mathrm{N}$ & $\%$ \\
\hline $1-10$ & 13 & 65,0 \\
$>10$ & 7 & 35,0 \\
\hline Total & 20 & 100,0 \\
\hline
\end{tabular}

Durasi kerja setiap responden dalam sehari ialah 8 jam (100\%) (Tabel 3).

Tabel 3. Distribusi responden berdasarkan durasi kerja (jam/hari)

\begin{tabular}{ccc}
\hline $\begin{array}{c}\text { Durasi kerja } \\
\text { (jam/hari) }\end{array}$ & $\mathrm{N}$ & $\%$ \\
\hline 8 Jam/hari & 20 & 100,0 \\
Total & 20 & 100,0 \\
\hline
\end{tabular}


Berdasarkan Tabel 4 durasi kerja setiap teknisi dalam seminggu ialah 7 hari (100\%).

Tabel 4. Distribusi responden berdasarkan durasi kerja (hari/minggu)

\begin{tabular}{ccc}
\hline $\begin{array}{c}\text { Durasi kerja } \\
\text { (hari/minggu) }\end{array}$ & $\mathrm{N}$ & $\%$ \\
\hline 7 hari/minggu & 20 & 100,0 \\
Total & 20 & 100,0 \\
\hline
\end{tabular}

Berdasarkan pengukuran dengan menggunakan Sound Level Meter didapatkan bahwa teknisi yang bekerja pada bagian pemeliharaan mesin tingkat kebisingan $87 \mathrm{~dB}$ lebih banyak yaitu 13 orang (65\%) dan 7 orang pada tingkat kebisingan $93 \mathrm{~dB}(35 \%)$.

Tabel 5. Distribusi responden berdasarkan tingkat intensitas bising

\begin{tabular}{ccc}
\hline Tingkat Bising & $\mathrm{N}$ & $\%$ \\
\hline $87 \mathrm{~dB}$ & 13 & 65,0 \\
$93 \mathrm{~dB}$ & 7 & 35,0 \\
Total & 20 & 100,0 \\
\hline
\end{tabular}

Berdasarkan hasil penelitian yang didapatkan petugas yang sering menggunakan APT berjumlah 10 orang (50\%) dan yang jarang menggunakan APT 10 orang (50\%).

Tabel 6. Distribusi responden berdasarkan ketaatan pemakaian Alat Pelindung Telinga (APT)

\begin{tabular}{ccc}
\hline Pemakaian APT & N & $\%$ \\
\hline Sering dipakai & 10 & 50,0 \\
Jarang dipakai & 10 & 50,0 \\
Total & 20 & 100,0 \\
\hline
\end{tabular}

Tabel 7 memperlihatkan bahwa pemakaian alat pelindung telinga jenis ear muff lebih banyak yaitu 11 orang (55\%) dibandingkan pemakaian jenis ear plug sebanyak 9 orang (45\%).

Tabel 8 dan 9 menunjukkan bahwa hasil pemeriksaan fungsi pendengaran dengan audiometri mendapatkan 3 orang (15\%) yang menderita tuli dan 17 orang
(85\%) normal.

Tabel 7. Distribusi responden berdasarkan jenis Alat Pelindung Telinga (APT) yang digunakan

\begin{tabular}{ccc}
\hline Jenis APT & $\mathrm{N}$ & $\%$ \\
\hline Ear Muff & 11 & 55,0 \\
Ear Plug & 9 & 45,0 \\
Total & 20 & 100,0 \\
\hline
\end{tabular}

Tabel 8. Distribusi responden berdasarkan gangguan pendengaran

\begin{tabular}{ccc}
\hline Hasil & $\mathrm{N}$ & $\%$ \\
\hline Normal & 17 & 85,0 \\
Tuli & 3 & 15,0 \\
Total & 20 & 100,0 \\
\hline
\end{tabular}

Tabel. 9. Berdasarkan lama kerja dan fungi pendengaran

\begin{tabular}{ccc}
\hline $\begin{array}{c}\text { Lama } \\
\text { Kerja }\end{array}$ & $\mathrm{N}$ & $\begin{array}{c}\text { Fungsi } \\
\text { Pendengaran }\end{array}$ \\
\hline 1 Tahun & 4 & Normal \\
2 Tahun & 1 & Normal \\
3 Tahun & 3 & Normal \\
4 Tahun & 2 & Normal \\
5 Tahun & 0 & - \\
6 Tahun & 1 & Normal \\
7 Tahun & 0 & - \\
8 Tahun & 0 & - \\
9 Tahun & 1 & Normal \\
10 Tahun & 1 & Normal \\
>10 Tahun & 7 & orang tuli, 4 \\
orang normal \\
Total & 20 & $\begin{array}{c}\text { Normal 17 orang, } \\
\text { 3 tuli }\end{array}$ \\
\hline
\end{tabular}

Berdasarkan hasil analisis bivariat dengan uji korelasi Spearman (rho) didapatkan nilai $\mathrm{p}=0,008(\mathrm{p}=<0,05)$

\section{BAHASAN}

Berdasarkan penelitian dapat dilihat bahwa teknisi dengan lama kerja 1-10 tahun lebih banyak berjumlah 13 orang (65\%) dibandingkan dengan yang bekerja $>10$ tahun. Pada Tabel 5 dapat dilihat bahwa teknisi yang bekerja dengan intensitas kebisingan $87 \mathrm{~dB}$ berjumlah 13 orang lebih banyak dibandingkan dengan teknisi yang bekerja pada intensitas kebisingan 93 dB yaitu 7 orang. Masa kerja 
$>10$ tahun dengan intensitas kebisingan lebih dari $85 \mathrm{~dB}$ lebih rentan mengalami penurunan pendegaran. ${ }^{5}$

Berdasarkan data kuesioner didapatkan bahwa teknisi yang sering menggunakan APT berjumlah 10 orang dan teknisi yang jarang menggunakan APT berjumlah 10. Dari 10 orang yang jarang menggunakan APT didapatkan 3 orang mengalami gangguan pendengaran dengan jenis ketulian sensorineural. Tuli sensorineural timbul secara bertahap, biasanya terjadi 8-10 tahun paparan. Pemeriksaan audiometri nada murni didapatkan tuli sensorineural nada tinggi (umumnya 3000-6000 Hz) dan pada frekwensi $4000 \mathrm{~Hz}$ sering terdapat takik (notc) yang patognomonik untuk jenis ketulian ini. ${ }^{6}$ Kenaikan ambang pendegaran mula-mula pada frekuensi $4000 \mathrm{~Hz}$, tetapi bila paparan berlangsung lama maka kenaikan nilai ambang batas sementara akan menyebar ke frekuensi lain. Kenaikan nilai ambang batas pendengaran akan menjadi permanen terutama pada intensitas frekuensi 3000-6000 Hz. ${ }^{7}$ Gangguan pendegaran akibat bising biasanya tidak disadari sampai ambang pendengaran bunyi nada percakapan yaitu 500, 1000, 2000, $3000 \mathrm{~Hz}$ dan $>25 \mathrm{~dB}^{8}{ }^{8}$ Derajat ketulian ditentukan berdasarkan ISO (International Standard Organitation) dengan patokan normal yaitu $0-25 \mathrm{~dB} .^{7}$

Penelitian Manoppo et al. ${ }^{9}$ pada petugas Operation dan Loading di Bandara Sam Ratulangi Manado. Penelitian dilakukan pada 20 orang petugas, yakni 9 orang petugas Loading dan 11 orang petugas Operation. Tingkat intensitas kebisingan dari kedua tempat ini berbeda yaitu petugas loading $75 \mathrm{~dB}$ dan petugas operation $85 \mathrm{~dB}$. Dari hasil penelitian ini didapatkan bahwa petugas loading tuli 1 orang, normal 8 orang dan petugas operation tuli 3 orang dan normal 8 orang.

Berdasarkan analisis bivariat dengan uji Spearman didapatan hasil yang signifikan dengan nilai $\mathrm{p}=0.008(<0.05)$. Faktor-faktor yang dapat menyebabkan seseorang menjadi tuli ialah frekuensi kebisingan, jenis kebisingan, masa kerja, sikap individu, dan kepatuhan individu memakai alat pelindung telinga. ${ }^{10}$ Pada penelitian ini, hasil analisis bivariat dengan uji Spearman mendapatkan hasil yang signifikan oleh karena teknisi yang bekerja pada intensitas bising $87 \mathrm{~dB}$ lebih sedikit mengalami gangguan pendengaran dibanding dengan teknisi yang bekerja pada intensitas $93 \mathrm{~dB}$. Selain itu, faktor-faktor seperti lama bekerja, lama paparan bising, dan penggunaan APT juga sangat berpengaruh terhadap terjadinya gangguan pendengaran pada teknisi.

\section{SIMPULAN}

Berdasarkan hasil penelitian dapat disimpulkan bahwa terdapat hubungan bermakna antara bising dan fungsi pendengaran pada teknisi mesin kapal di pelabuhan Bitung.

\section{SARAN}

Bagi responden, kesadaran menggunakan Alat Pelindung Telinga perlu ditingkatkan karena dapat membantu mengurangi paparan bising dalam mencegah terjadinya gangguan pendengaran.

\section{DAFTAR PUSTAKA}

1. Permatasari YA. Hubungan Tingkat Kebisingan dengan Gangguan Psikologis Pekerja di Bagian Weaving di PT. X Batang, Jawa Tengah. Jurnal Kesehatan Masyarakat. 2013;2(1). Available from: http: //ejournals1.undip.ac.id/index.php.

2. Bashiruddin J, Soetirto I. Buku Ajar Ilmu Kesehatan Telinga Hidung Tenggorok Kepala dan Leher (Edisi 7). Jakarta: Fakultas Kedokteran Universitas Indonesia; p. 42.

3. Tjan H, Lintong F, Supit W. Efek Bising Elektronika terhadap Gangguan Fungsi Pendengaran pada Pekerja di Kecamatan Sario Kota Manado, Sulawesi Utara. eBM. 2013;1(1):34-49.

4. Permaningtyas LD, Darmawan AB, Krisnansari D. Hubungan Lama Masa Kerja Dengan Kejadian Noise-Inducted Hearing Loss pada Pekerja Home Industry Knalpot di Kelurahan Purbalingga Lor. Mandala of Health. 
2011;5(3). Available from: http://kedokteran.unsoed.ac.id/Files/Jur nal/mandala\%

20september\%202011/HUBUNGAN\%

20LAMA\%20MASA\%20KERJA\%20

DENGAN\%20KEJADIAN\%20NOISE

INDUCED\%20HEARING\%20LOSS\%

20PADA\%20PEKERJA\%20HOME\%2

OINDUSTRY\%20KNALPOT.pdf.

5. Tana L, Halim FS, Ghani L, Delima.

Gangguan Pendengaran Akibat Bising pada Pekerja Perusahaan Baja di Pulau Jawa. J Kedokter Trisakti. 2002;21(3).84-90.

6. Christopher AP. Noise Induced Hearing Loss (NIHL). Faculty of Medicine University of Riau Pekanbaru. Riau. 2009. Available from: https://yayanakhyar.files. wordpress. com/2009/02/noise-induced-hearingloss-nihl-files-of-drsmed.pdf.

7. Kusmindari CD. Pengaruh Intensitas Kebisingan pada Proses Sugu dan Proses Ampelas Terhadap Pendengaran Tenaga Kerja di Bengkel Kayu X. TEKNO. 5(2). Palembang. 2008. http://blog.binadarma.ac.id/desi/wpcontent/uploads/2011/03/04-desiintensitas-bunyi-edit-desi.pdf.

8. Satriawan R. Gangguan Pendengaran akibat Bising. Lampung: RSUD
Ahmad Yani, Metro, Lampung 2012. Available from: https://ml.scribd.com/doc/180034967/ Gangguan-pendengaran-akibat-bisingfkuii-dr-rully-satriawan-lampung-pdf.

9. Manoppo F, Supit W, Danes VR. Hubungan Antara Kebisingan dan Fungsi Pendengaran pada Petugas PT. Gapura Angkasa di Bandar Udara Sam Ratulangi Manado. Manado. Fakultas Kedokteran Universitas Sam Ratulangi. 2013.

http://download.portalgaruda.org/articl e.php?article $=146423 \& v a l=1008 \&$ title $=$ HUBUNGAN\%20ANTARA\%20KE BISINGAN\%20DAN\%20FUNGSI\%2 OPENDENGARAN\%20PADA\%20PE TUGAS\%20PT.\%20GAPURA\%20AN GKASA\%20DI\%20BANDAR\%20UD ARA\%20SAM\%20RATULANGI\%20 MANADO.

10.Listyaningrum AW. Pengaruh Intensitas Kebisingan Terhadap Ambang Dengar pada Tenaga Kerja di PT. Sekar Bengawan Kabupaten Karanganyer. [Skripsi]. Surakarta: Fakultas Kedokteran Universitas Sebelas Maret, 2011. Available from: eprints.uns.ac.id/3763/1/203030811201 111431.pdf. 